\title{
Effect of green tea consumption on blood lipids: a systematic review and meta- analysis of randomized controlled trials
}

\author{
Renfan $\mathrm{Xu}^{1}$, Ke Yang ${ }^{2}$, Sui $\mathrm{Li}^{2}$, Meiyan Dai ${ }^{2}$ and Guangzhi Chen ${ }^{2^{*}}$ (D)
}

\begin{abstract}
Background: Strong epidemiologic evidence indicates that green tea intake is protective against hyperlipidemia; however, randomized controlled studies have presented varying results. In the present study, we aimed to conduct a literature review and meta-analysis to assess the effect of green tea on blood lipids.

Methods: PubMed, Embase, and the Cochrane Library were electronically explored from inception to September 2019 for all relevant studies. Random effect models were used to estimate blood lipid changes between green tea supplementation and control groups by evaluating the weighted mean differences (WMD) with 95\% confidence intervals (Cls). The risk of bias for study was assessed using the Cochrane tool. Publication bias was evaluated using funnel plots and Egger's tests.
\end{abstract}

Results: Thirty-one trials with a total of 3321 subjects were included in the meta-analysis. In general, green tea intake significantly lowered the total cholesterol (TC); WMD: $-4.66 \mathrm{mg} / \mathrm{dL} ; 95 \% \mathrm{Cl}:-6.36,-2.96 \mathrm{mg} / \mathrm{dL} ; P<0.0001$ ) and lowdensity lipoprotein (LDL) cholesterol (WMD:- $4.55 \mathrm{mg} / \mathrm{dL} ; 95 \% \mathrm{Cl}:-6.31,-2.80 \mathrm{mg} / \mathrm{dL} ; P<0.0001$ ) levels compared with those in the control. Green tea consumption did not affect high-density lipoprotein (HDL) cholesterol; however, it reduced the triglycerides compared with that in the control (WMD: $-3.77 \mathrm{mg} / \mathrm{dL} ; 95 \% \mathrm{Cl}:-8.90,1.37 \mathrm{mg} / \mathrm{dL} ; P=0.15)$. In addition, significant publication bias from funnel plots or Egger's tests was not evident.

Conclusions: Collectively, consumption of green tea lowers LDL cholesterol and TC, but not HDL cholesterol or triglycerides in both normal weight subjects and those who were overweight/obese; however, additional welldesigned studies that include more diverse populations and longer duration are warranted.

Keywords: Green tea, Catechin, Cholesterol, Triglycerides, Meta-analysis

\section{Introduction}

Cardiovascular diseases (CVDs) are the leading cause of mortality and disability worldwide, accounting for approximately17.3 million deaths per year [1]. Hyperlipidemia, resulting from abnormalities due to lipid metabolism, causes atherosclerotic plaques and is considered a major risk factor for CVDs [2]. The previous study reports that

\footnotetext{
* Correspondence: chengz2003@163.com

${ }^{2}$ Division of Cardiology, Department of Internal Medicine, Tongji Hospital, Tongji Medical College, Huazhong University of Science and Technology, Wuhan 430030, People's Republic of China

Full list of author information is available at the end of the article
}

subjects with hyperlipidemia have a three-fold risk of heart attack compared with those with normal lipid levels [3]. Moreover, CVDs risk was found to reduce by $3 \%$ when the serum cholesterol decreased by $1 \%$ [4]. Although several synthetic lipid-lowering medications (fibrates, statins, and bile acid sequestrants) are available in the market, their long-term usage might result in various adverse effects [5]. Agencies concerned with cardiovascular health have uniformly stressed the importance of lifestyle and diet as the primary means of lowering serum lipids and CVDs risk [6].

(c) The Author(s). 2020 Open Access This article is licensed under a Creative Commons Attribution 4.0 International License, which permits use, sharing, adaptation, distribution and reproduction in any medium or format, as long as you give appropriate credit to the original author(s) and the source, provide a link to the Creative Commons licence, and indicate if changes were made. The images or other third party material in this article are included in the article's Creative Commons licence, unless indicated otherwise in a credit line to the material. If material is not included in the article's Creative Commons licence and your intended use is not permitted by statutory regulation or exceeds the permitted use, you will need to obtain permission directly from the copyright holder. To view a copy of this licence, visit http://creativecommons.org/licenses/by/4.0/ The Creative Commons Public Domain Dedication waiver (http://creativecommons.org/publicdomain/zero/1.0/) applies to the data made available in this article, unless otherwise stated in a credit line to the data. 
Green tea, which is derived from the plant Camellia sinensis, is a popular beverage worldwide, and can delay the onset or progression of numerous diseases such as cardiovascular disorders, metabolic diseases, and hypertension [7, 8]. Tea polyphenols, specifically catechins (flavonoids), are crucial in promoting health. The four major catechins (constituting 25-30\%) reported in green tea are epicatechin (EC), epigallocatechin (EGC), epicatechingallate (ECG), and epigallocatechin gallate (EGCG) [9]. EGCG is most abundant (50-60\% of total catechins), and has anti-inflammatory, antioxidant, anticarcinogenic, and antiobesity properties [10,11]. Green tea also contains theaflavins, caffeine, phenolic acids, and flavonols such asquercetin, kaempferol, and myricetin [12].

Both in vitro and animal experiments have shown that green tea catechins can significantly reduce the levels of plasma triglycerides, total cholesterol (TC), and lowdensity lipoprotein (LDL) cholesterol [11, 12]. However, clinical trial results have not been conclusive regarding these effects of green tea. Some randomized controlled trials (RCTs) and meta-analyses have suggested that green tea may affect the lipid profiles in subjects with cardiovascular-related diseases such as hypercholesterolemia, hypertension, and glucose intolerance as well as in healthy individuals $[13,14]$, whereas other RCTs have not been able to confirm the positive metabolic effects of green tea $[15,16]$.

In this article, we report a systematic review and metaanalysis of RCTs to quantitatively assess the effect of green tea on total cholesterol, LDL, HDL, and triglyceride levels based on the Preferred Reporting Items for Systematic Reviews and Meta-Analyses (PRISMA) guidelines [17].

\section{Methods}

\section{Search strategy and eligibility criteria}

We explored PubMed, Embase, and the Cochrane Library from the index date of each database through September 2019 by using the following terms: "green tea," "tea component(s)," "green tea extract," "tea solid(s)," "catechins," "EGCG," "Camellia sinensis," and "tea polyphenols," which were paired with the following words: "blood lipid," "blood cholesterol," "high-density lipoprotein cholesterol," "low-density lipoprotein cholesterol," "triglyceride," or "cardiovascular." We further restricted the search to studies on humans and to English articles. Additional studies not captured by our database search were retrieved via a manual search of references from the originally identified reviews and research reports.

\section{Study selection}

The prespecified inclusion criteria were as follows: 1) adult subjects who had ingested green tea for $\geq 2$ weeks; 2) use of an RCT design; 3) trial reported effects on TC,
LDL cholesterol, HDL cholesterol, or triglycerides;4) green tea extract not being administered as part of a multicomponent supplement in either the experimental or control group; 5) the study used a concurrent control group; the only difference between the treatment and control groups was the use of green tea or green tea extract; and 6) each group in the trial enrolled $>10$ participants. The exclusion criteria were as follows: 1 ) trials that enrolled children or pregnant women;2) trials in which green tea was included as part of a calorie-containing beverage, for example, milk or fruit juice. The data of multiple published reports from the same study population were included only once.

\section{Assessment of risk of bias in included studies}

Two authors (CGZ and XRF) independently assessed the risk of bias of each study, using the Cochrane tool for assessing risk of bias [18]. Any disagreement was resolved by discussion between the third author (YK). The risk of bias tool addresses the following domains: Bias arising from the randomisation process; Bias due to deviations from intended interventions; Bias due to missing outcome data; Bias in measurement of the outcome; Bias in selection of the reported result and overall bias. For each study we categorized each domain as 'low risk of bias', 'high risk of bias' or 'Some concerns'. The overall risk of bias generally corresponds to the worst risk of bias in any of the domains. However, if a study is judged to have "some concerns" about risk of bias for multiple domains, it might be judged as at high risk of bias overall.

\section{Data extraction}

We extracted all data using a standardized data collection form. The following information was sought from each article: study characteristics (the first author, year of publication, study design, sample size, study duration, intervention type and dose), participant characteristics (age, sex, country, and baseline cholesterol status), and mean differences in the levels of TC, LDL, HDL, and triglycerides, representing the primary outcome measures. Two authors (CGZ and XRF) independently extracted the data, and any disagreements were resolved by discussion with a third author (YK). All values were converted to milligram per deciliters $(\mathrm{mg} / \mathrm{dL})$ in this trial. Although outcomes were reported several times at different stages of the trials, only the final outcome concentrations, at the end of the trial, were included in the meta-analysis.

\section{Statistical analysis}

We performed this meta-analysis by using STATA statistical software (version 11; STATA Corp LP). Treatment effects were defined as the mean differences and 95\% confidence intervals (CIs) calculated for changes in 
TC, LDL, HDL, and triglyceride levels between the intervention and control groups from baseline to the end of the intervention period. Pooled estimated effects were calculated by assigning each study a weight of the reciprocal of its variance. If the standard deviations (SDs) were not reported directly, then the variances were imputed from $P$ values, 95\% CIs, standard error (SE), or $t$ values [19]. In addition, missing SD values for paired differences were imputed by assuming a correlation coefficient of 0.5 between the variances at baseline and end of trial according to the method by Follmann et al. [20]. Random-effects models (DerSimonian and Laird), which considered both within- and between-study variation, were performed for the studies used different doses, different populations, different durations and so on.

Statistical heterogeneity was estimated by using Cochran's test $(P<0.10$ was considered statistically significant) and heterogeneity was quantified with the $\mathrm{I}^{2}$ statistic. $I^{2}>50 \%$ indicated significant heterogeneity across studies [21]. Prespecified subgroup analyses were performed according to: catechin dosage $(\geq 615 \mathrm{mg} /$ day, high median vs. $<615 \mathrm{mg} /$ day, low median); green tea intervention duration ( $\geq 12$ weeks, long-term vs. $<12$ weeks, short-term); intervention type (green tea beverage or green tea capsule); participant ethnicity (Asian or Western countries); study design (parallel or crossover); health status of participants (healthy subjects vs. obese subjects). Furthermore, meta-regression analysis was performed to examine the association between the net change in serum lipids and intervention dose, treatment duration, intervention type, caffeine content, different ethnicity and study design. Sensitivity analyses were performed to assess the stability of the results by removing one study each time to identify the impact of individual studies on the pooled effect size. Funnel plots and Egger's regression test were used to assess the publication bias [22]. A $P$ value of $<0.05$ was considered statistically significant in this trial, unless otherwise specified.

\section{Results}

Results of the literature search

The detailed process of the study selection is depicted in Fig. 1. In total, 1736 potentially relevant articles were initially identified from PubMed, EMBASE, and the

Potentially relevant articles $(\mathrm{n}=1736)$

Pubmed: 818

Embase: 756

Cochrane: 152

Manual search: 10

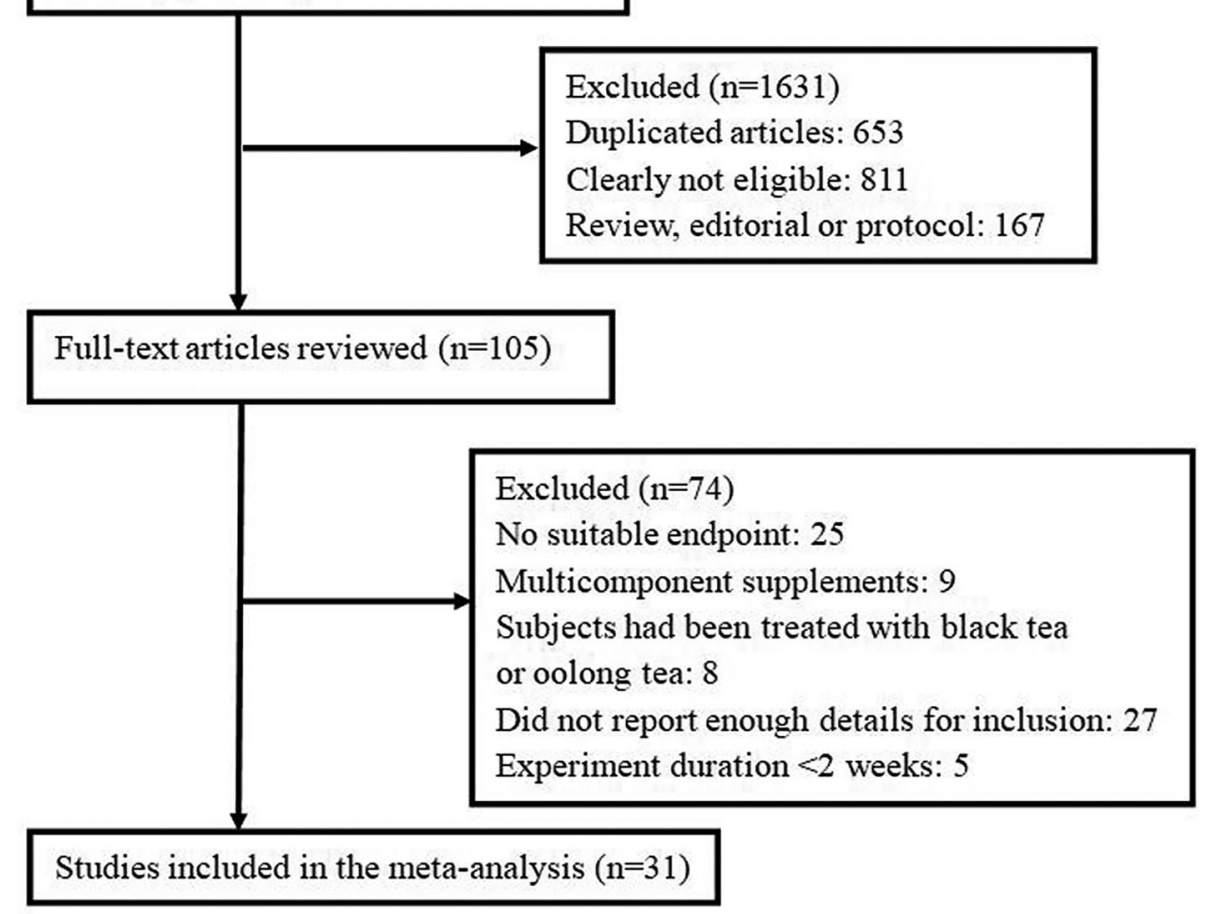

Fig. 1 Flow diagram of the study selection procedure presenting the number of eligible articles included in the meta-analysis 
Cochrane Library, collectively with manually searched articles. A total of 1631 articles were excluded, either because of duplication or because they were deemed irrelevant on the basis of the article title and abstract screening. We included 105 articles in the full-text review during which 74 articles were excluded for various reasons: 27 articles did not report enough details for inclusion, 25 articles did not report relevant outcomes, 8 articles were excluded because the subjects had been treated with black tea or oolong tea, 5 studies were $<2$ weeks in duration, 9 studies used green tea a multicomponent supplement in the experimental group. Thus, 31 articles were eventually selected for inclusion in the meta-analysis.

\section{Study characteristics}

Thirty-one eligible RCTs with a total of 3216 subjects were enrolled in the meta-analysis [23-53]. Trial characteristics are summarized in Table 1 . In these trials, the study duration ranged from 3 weeks to 12 months, trial size varied from 20 to 936 subjects, green tea catechin intake in the intervention groups ranged from 80 to $2488.7 \mathrm{mg} / \mathrm{d}$. We included 31 trials with 33 comparisons in this meta-analysis. Thirty-one comparisons reported on total cholesterol ( $n=3024$ subjects) [23-36, 38-40, 42-53], 29 comparisons reported on LDL cholesterol $(n=3005)$ [23-29, 32-40, 42-44, 46-53], 29 comparisons reported on HDL cholesterol $(n=3073)$ [23-30, $32-36,38-44,47-53]$ and 29 comparisons reported on outcomes for triglycerides $(n=3025$ subjects) [23-29, 31-36, 38-41, 43-45, 47-53]. Sixteen comparisons were conducted in western countries [23-26, 29-31, 40, 42, $46-48,50,53]$ and 17 comparisons were conducted in Asian countries [27, 28, 32-39, 41, 43-45, 49, 51, 52]. Twelve comparisons were performed in healthy normal weight subjects [31, 36, 39, 43, 46-49, 52, 53], and 21 comparisons were conducted in over-weight to obese patients [23-30, 32-35, 37, 38, 40-42, 44, 45, 50, 51]. Most of the comparisons (30/33) used a parallel study design [23-25, 27-31, 33, 34, 36-53], whereas 3 comparisons adopted a crossover design [26, 32, 35]. Fourteen comparisons ruled out the confounding effect of caffeine on lipid concentrations [23, 25, 26, 28, 34, 35, 37-39, 42, 46, 48, 53], 12 comparisons used caffeinated green tea as supplements [27, 29-33, 40, 43-45, 49, 52] and 7 did not report the use of coffee [24, 36, 41, 47, 50, 51]. Nine comparisons selected green tea beverage [23, $32,40,43-45,47,49,52]$, and 24 comparisons used green tea extract capsule [24-31, 33-39, 41, 42, 46-48, 50, 51, 53] (Table 1).

\section{Risk of bias}

Overall nine of the 31 studies were at low overall risk of bias with no items at unclear or high risk of bias $[25,26$,
$28,33,34,39,42,48,51]$; two were at unclear risk of bias with no items at high risk of bias [35, 52]; and 20 were at high risk of bias [23, 24, 27, 29-32, 36-38, 40, 41, 43-47, 49, 50, 53] (Fig. 2). The risk of bias judgments and the details for each trial are in supplementary Table 1.

\section{Main outcomes}

Primary outcome measures included changes in TC, LDL cholesterol, HDL cholesterol, and triglycerides. Thirty-one studies representing 3024 participants reported results for serum TC concentrations. Collectively, a significant difference was observed in the serum TC level in the green tea supplementation and the control groups (weighted mean difference: $-4.66 \mathrm{mg} / \mathrm{dL}$; $95 \%$ CI: $-6.36,-2.96 \mathrm{mg} / \mathrm{dL} ; P<0.0001)$. This difference represents a $2.3 \%$ decrease in the TC concentration while consuming green tea. Heterogeneity was not significant for this outcome $\left(\mathrm{I}^{2}=23.2 \%, P=0.124\right.$; Fig. 3$)$.

Results for LDL cholesterol were reported in 29 studies representing 3005 participants. Green tea supplementation significantly reduced the LDL cholesterol by $-4.55 \mathrm{mg} / \mathrm{dL}$ (95\% CI: $-6.31,-2.80 \mathrm{mg} / \mathrm{dL} ; P<0.0001$ ) compared with the placebo effects. The degree of heterogeneity was significant $\left(\mathrm{I}^{2}=28.1 \% ; P=0.082\right)$ (Fig. 4).

The mean change in HDL cholesterol concentrations was reported in 29 studies, which represented 3073 participants. In general, no significant difference was observed in serum HDL between the green tea supplementation and placebo groups (weighted mean difference: $0.23 \mathrm{mg} /$ $\mathrm{dL} ; 95 \% \mathrm{CI}:-0.45,0.91 \mathrm{mg} / \mathrm{dL} ; P=0.50$ ). The overall result for the heterogeneity test was significant $\left(\mathrm{I}^{2}=34.8 \%\right.$; $P=0.035$ ) (Fig. 5).

Serum triglyceride concentrations were calculated in 29 comparisons that included 3025 subjects. Although differences in triglyceride levels did not attain statistical significance, we observed a trend in favor of green tea $3.77 \mathrm{mg} / \mathrm{dL}(95 \% \mathrm{CI}:-8.90,1.37 \mathrm{mg} / \mathrm{dL} ; P=0.15)$. Large heterogeneity $\left(\mathrm{I}^{2}=56.5 \% ; P=0.0001\right)$ was observed in this outcome (Fig. 6).

\section{Subgroup analysis and meta-regression}

In the subgroup analysis, the beneficial effect of green tea intake on total cholesterol was consistently observed in all the analyses except for the study design subgroups. Green tea consumption significantly lowered TC in subgroups with parallel design, but no effect was found in the subgroup with crossover design. In addition, the beneficial effect of green tea intake on LDL cholesterol was also consistently observed in most subgroup analyses except for the decaffeination subgroup. A significant reduction in LDL cholesterol was observed in the decaffeination subgroup; however, no effect was observed in the caffeine subgroup. Meta-analysis indicated that green tea has no effect on serum HDL cholesterol, 


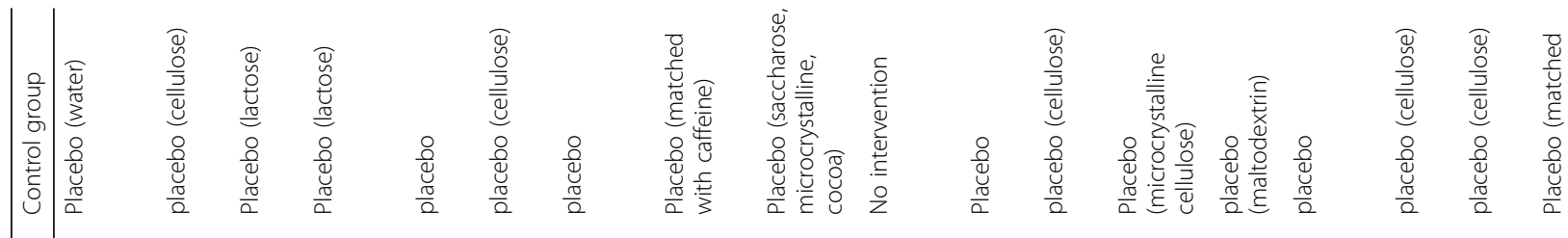

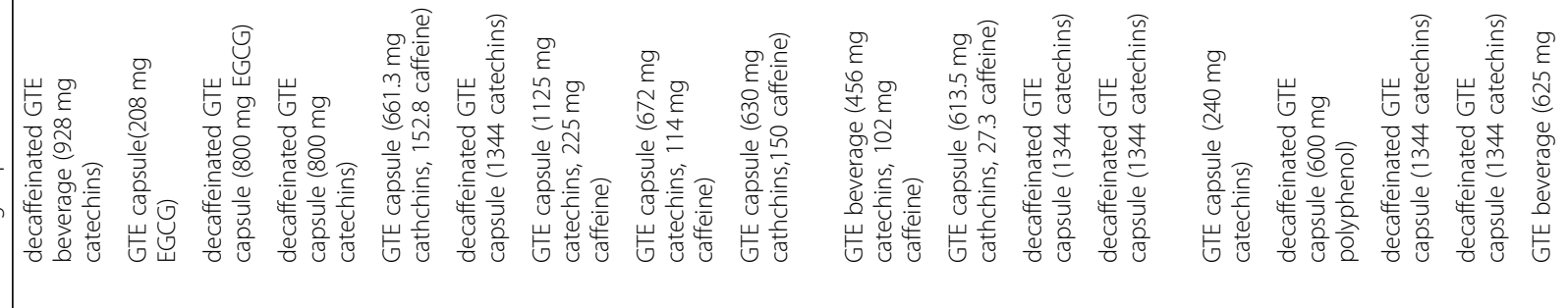

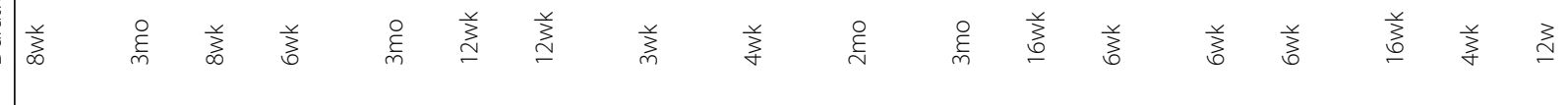

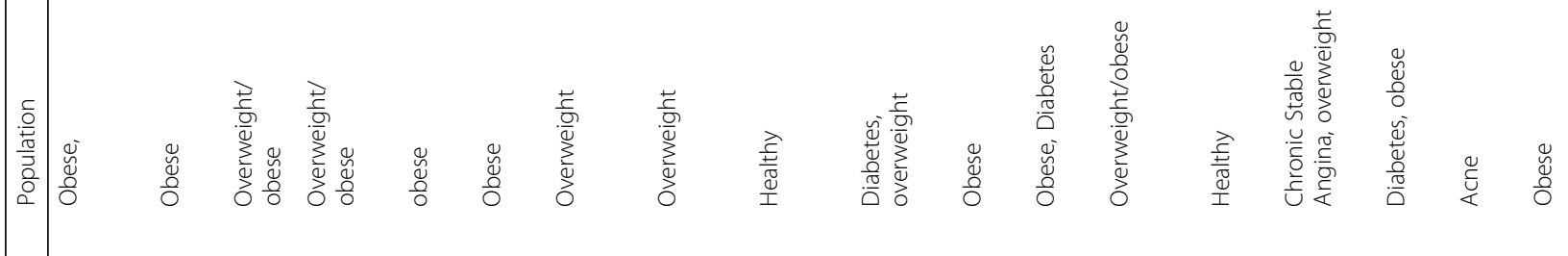

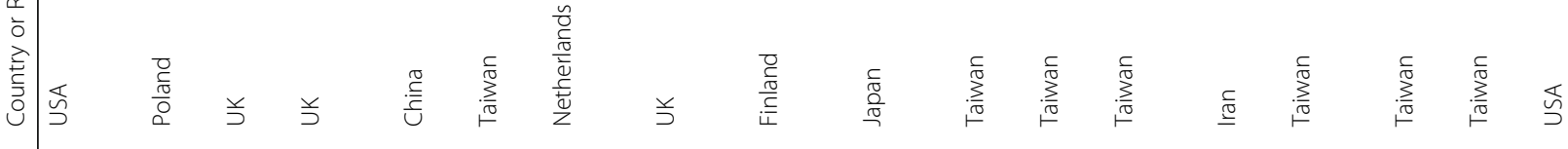

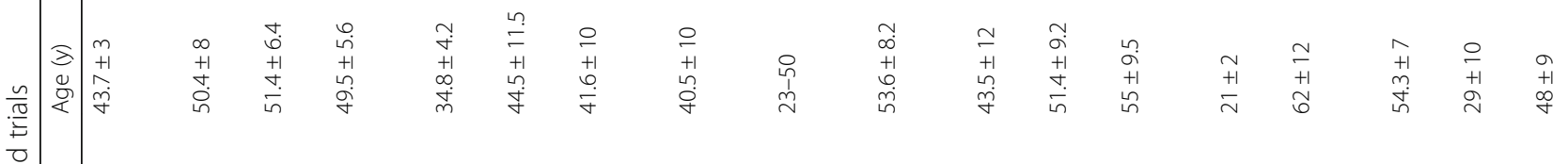

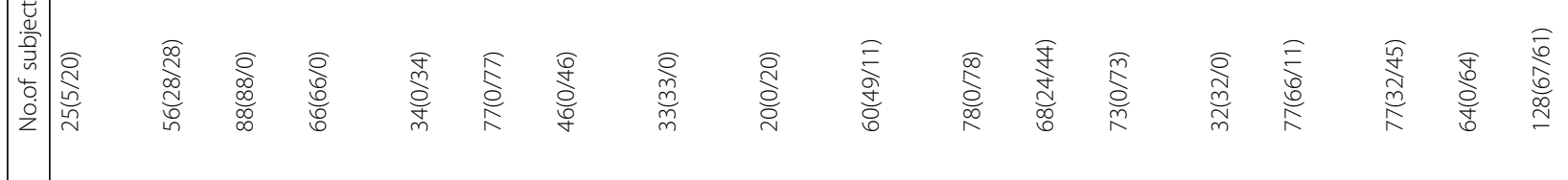

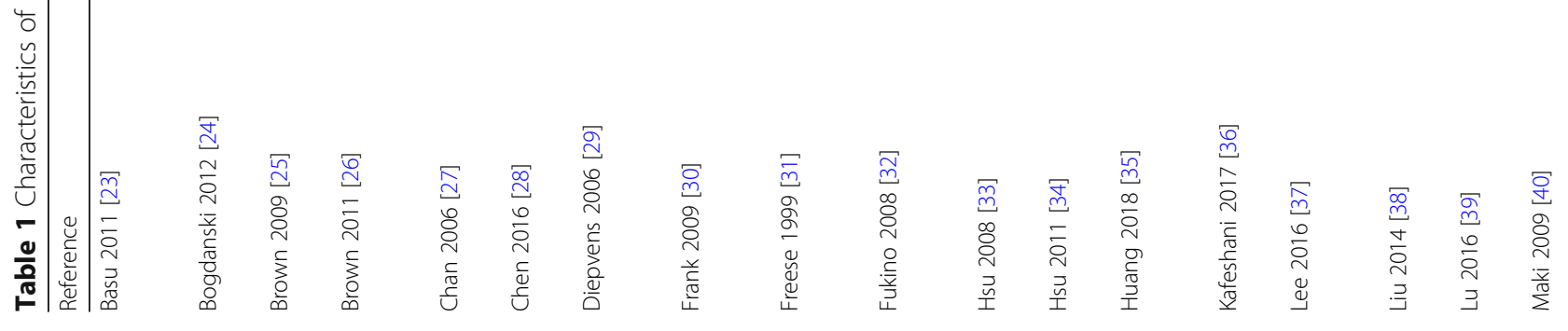




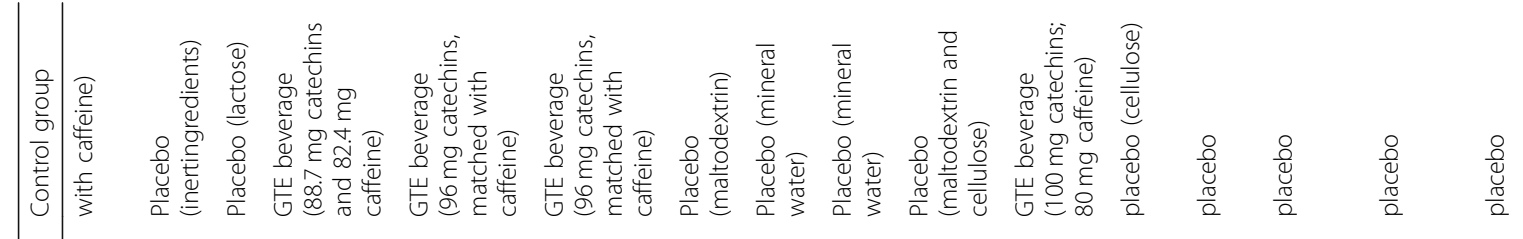

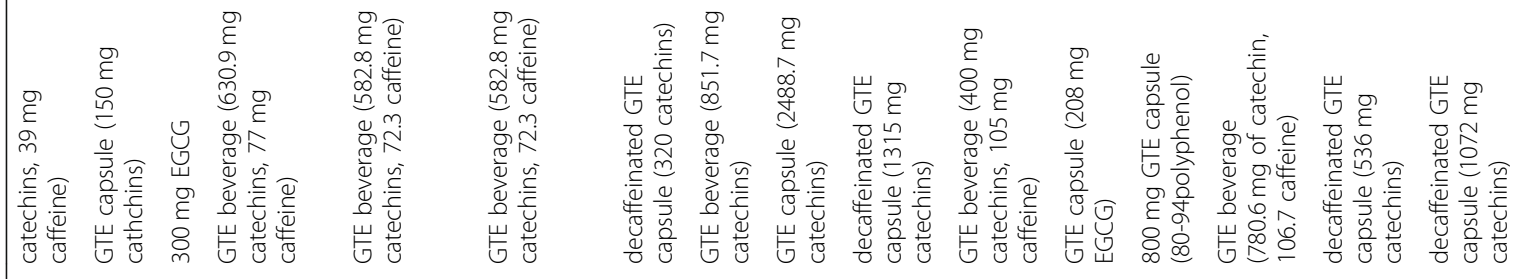


Bias arising from the randomisation process

Bias due to deviations from intended interventions

Bias due to missing outcome data

Bias in measurement of the outcome

Bias in selection of the reported result

Overall bias assessment
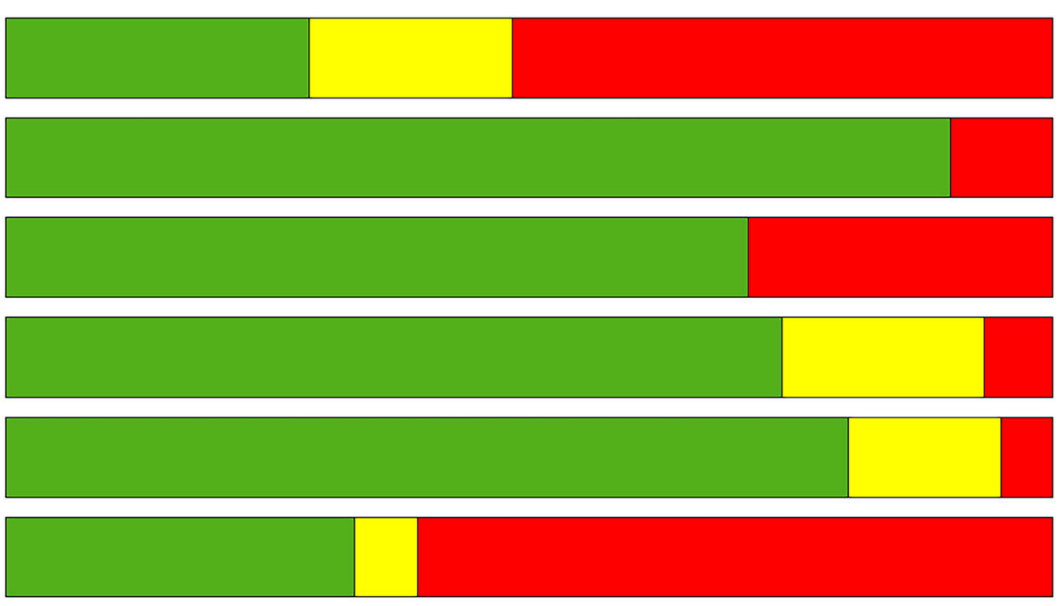

$0 \%$

$25 \%$

Fig. 2 Risk of bias summary: review authors' judgements about each risk of bias item for included studies

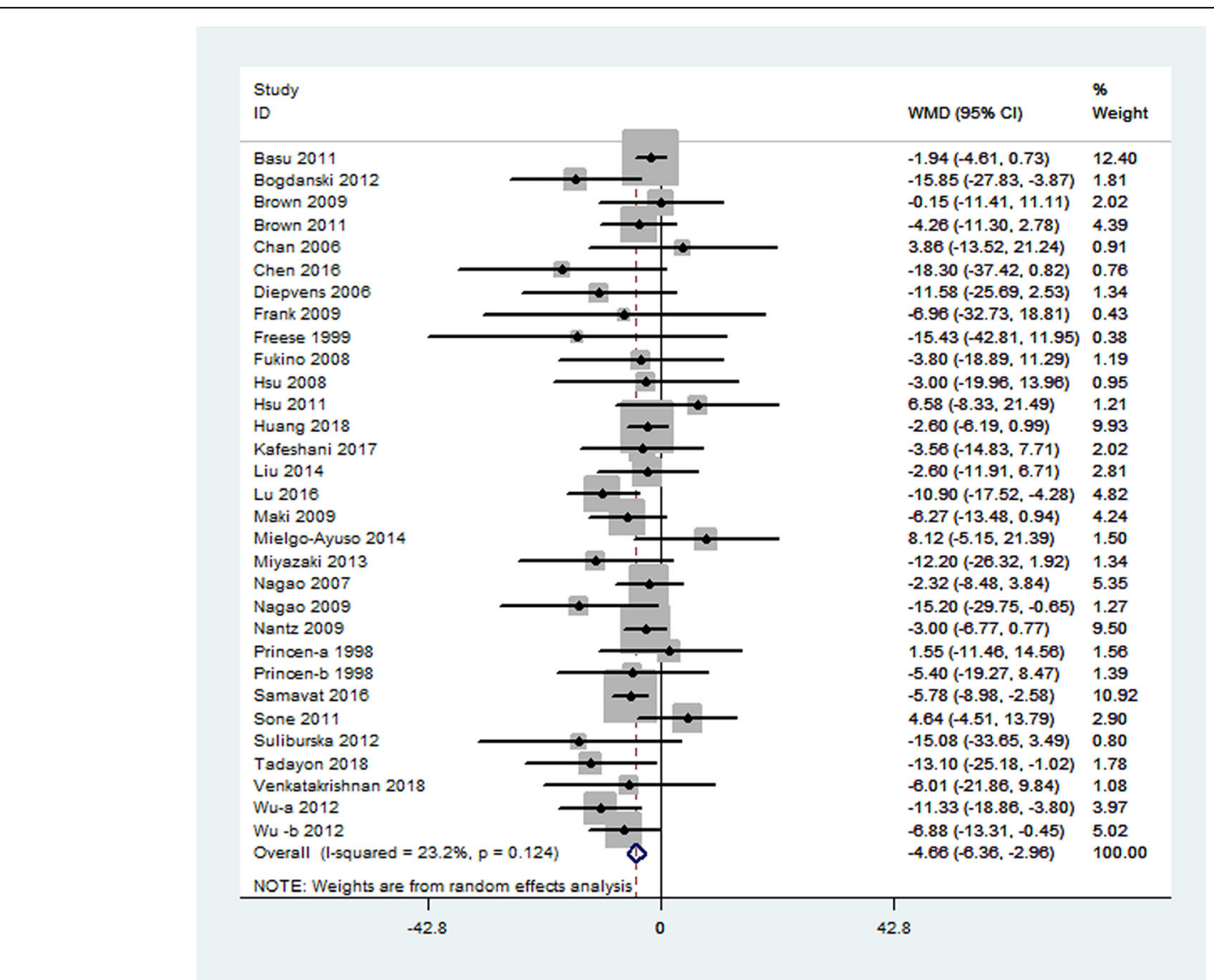

Fig. 3 Meta-analysis of the effects of green tea on total cholesterol concentrations. Results from individual trials were pooled with the use of random-effect models and are expressed as weighted mean differences with 95\% Cls 


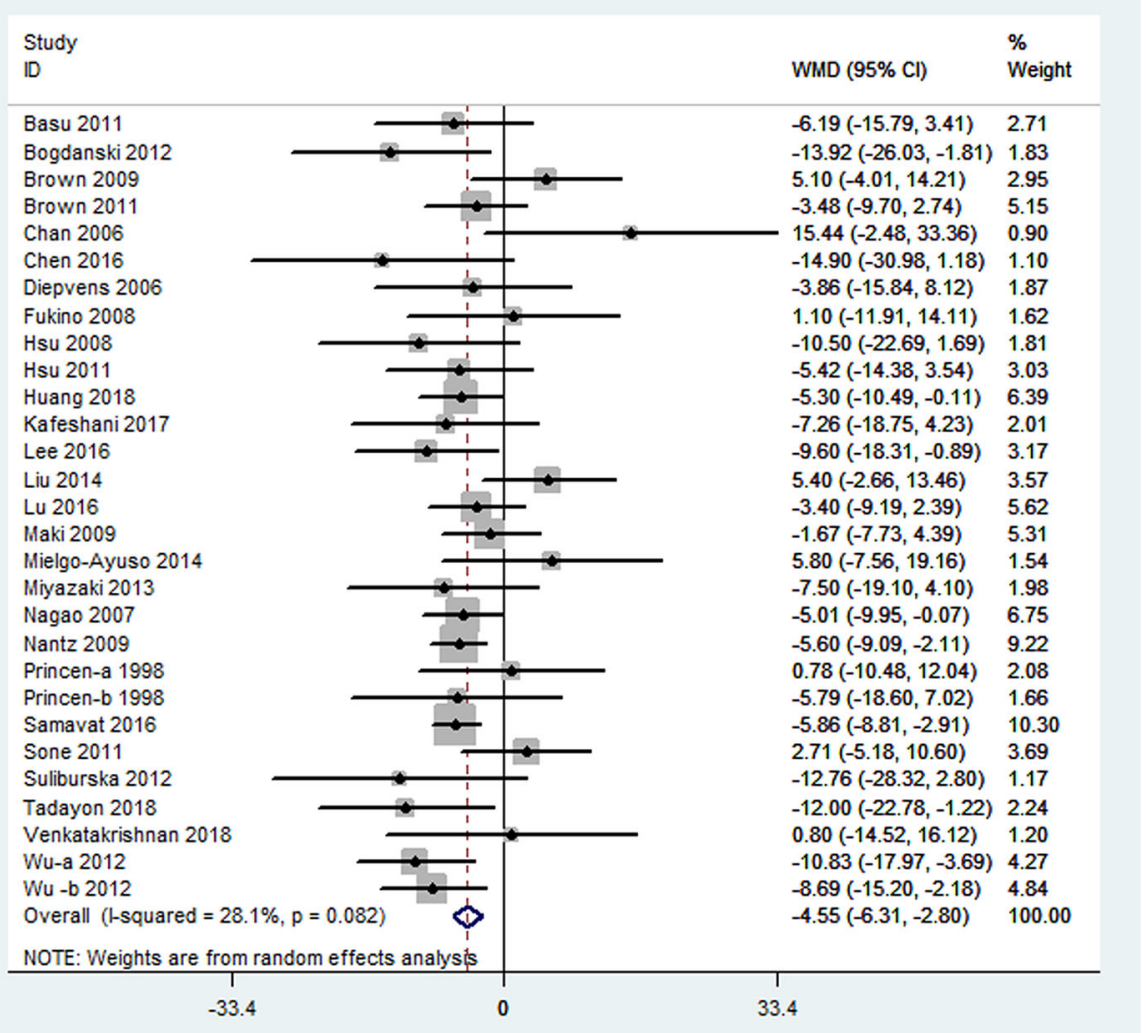

Fig. 4 Meta-analysis of the effects of green tea on LDL cholesterol concentrations. Results from individual trials were pooled with the use of random-effect models and are expressed as weighted mean differences with 95\% Cls. LDL cholesterol: low-density lipoprotein cholesterol

which was consistent in all the subgroup analyses. Subgroup analysis suggested that triglycerides were reduced to a greater degree in the studies with longer duration subgroup, with mean changes of $-9.03 \mathrm{mg} / \mathrm{dL}$ (95\% CI: - 17.92, $-0.15 \mathrm{mg} / \mathrm{dL} ; P=0.04$ ); however, no effect of green tea on triglycerides was observed in other subgroup analysis (Table 2).

Meta-regression found no linear relations between net change in TC, LDL cholesterol, HDL cholesterol or triglycerides and intervention dose (Fig. 7). Furthermore, meta-regression found no linear relations between net change in serum lipid and treatment duration, caffeine content, different ethnicity, intervention type and study design.

\section{Publication bias}

The funnel plots of the studies were symmetrical for TC, LDL cholesterol, HDL cholesterol, and triglyceride (supplementary Figure 1). Furthermore, Egger's test suggested that no strong evidence was seen for a publication bias for TC $(P=0.63)$, LDL cholesterol $(P=0.54)$, HDL cholesterol $(P=0.43)$, or triglycerides $(P=0.36)$.
A sensitivity analysis was performed to confirm the robustness of our findings, in which one study at a time was excluded and the rest were analyzed; herein, the pooled reductions in TC ranged from $-4.77 \mathrm{mg} / \mathrm{dL}(95 \%$ CI: $-6.40,-3.14 \mathrm{mg} / \mathrm{dL})$ to $-4.26 \mathrm{mg} / \mathrm{dL}(95 \% \mathrm{CI}:-$ $5.90,-2.63 \mathrm{mg} / \mathrm{dL}$ ); the pooled reductions in LDL cholesterol ranged from $-4.85 \mathrm{mg} / \mathrm{dL}$ (95\% CI: - 6.57, $3.13 \mathrm{mg} / \mathrm{dL}$ ) to $-4.29 \mathrm{mg} / \mathrm{dL}$ (95\% CI: $-6.04,-2.54 \mathrm{mg} /$ $\mathrm{dL})$; the pooled reductions in HDL cholesterol ranged from $0.09 \mathrm{mg} / \mathrm{dL}(95 \% \mathrm{CI}:-0.56,0.75 \mathrm{mg} / \mathrm{dL})$ to 0.37 $\mathrm{mg} / \mathrm{dL}$ ( $95 \% \mathrm{CI}:-0.26,0.99 \mathrm{mg} / \mathrm{dL}$ ); and the pooled reductions in triglyceride ranged from $-4.50 \mathrm{mg} / \mathrm{dL}(95 \%$ CI: $-9.61,0.61 \mathrm{mg} / \mathrm{dL}$ ) to $-2.49 \mathrm{mg} / \mathrm{dL}$ (95\% CI: -7.27 , $2.30 \mathrm{mg} / \mathrm{dL}$ ); removing a single trial did not hamper the study significance.

\section{Discussion}

The present meta-analysis evaluated the association between green tea consumption and reduction in serum lipid concentrations based on published results from 31 studies comprising 3216 subjects. The results suggest that green tea supplementation significantly lowered both serum TC and LDL cholesterol concentrations. In 


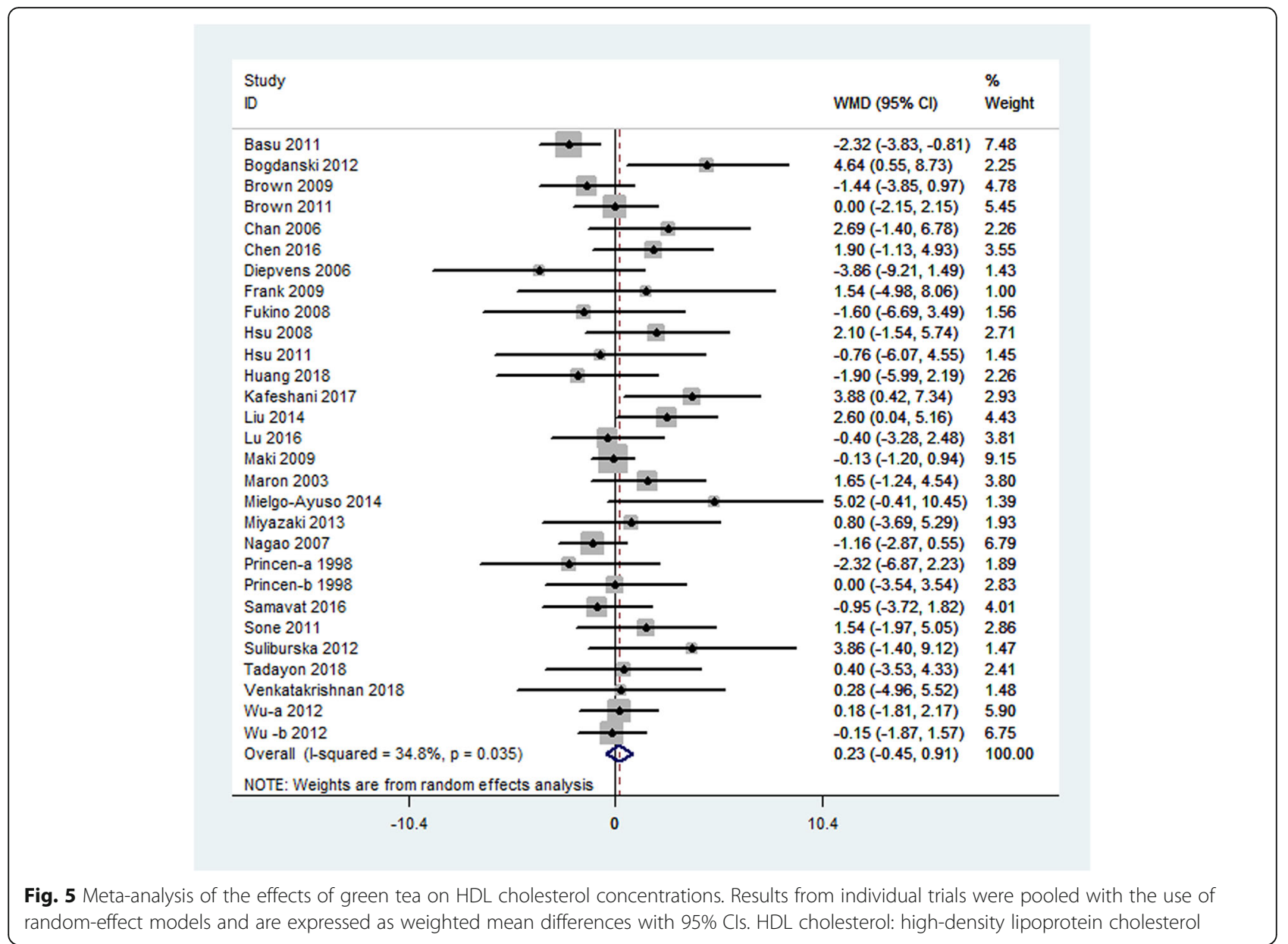

addition, we demonstrated a trend toward decrease in triglyceride concentrations, although it did not attain significance, presumably because of the limited participants or duration for which the triglyceride concentrations were reported; however, green tea did not significantly affect the levels of HDL cholesterol. These findings are generally in accordance with the results from previous meta-analyses, which also identified a significant correlation between green tea supplementation and improvements in TC and LDL cholesterol concentration [13].

Recent mechanistic studies have examined the effects of green tea intake on lipid control and provide further evidence for the biological plausibility of these findings. In accordance with our results, several animal studies have reported that green tea supplementation significantly improved hyperlipidemia status in high-fat diet induced rats, including lowering TC, LDL cholesterol, and triglycerides [54]. Moreover, recent animal studies have indicated that green tea catechins could significantly inhibit atherosclerotic plaque formation, lower liver fat accumulation, and increase HDL cholesterol in hyperlipidemic rats induced by high-fat andhigh- cholesterol diet [55]. The mechanism underlying the beneficial effect of green tea on lipid control may be attributed to the high concentration of green tea catechins, which involve the following aspects:

(1) EGCG could attenuate the endothelial dysfunction induced by oxidized-LDL via the Jagged-1/Notch signaling pathway in human umbilical vein endothelial cells, which provides a beneficial effect by inhibiting the atherosclerotic plaque formation [56]. (2) Tea catechins are powerful antioxidants that prevent LDL oxidation by incorporating themselves into LDL particles in nonconjugated forms in vitro [57]. (3) These are responsible for LDL receptor binding activity upregulation in HepG2 cells in a dose-dependent manner by regulating the SREBP-1 (sterol regulatory binding protein-1) pathway [58]. (4) Green tea might also inhibit intestinal lipid absorption by interfering with micelle formation [59].

Observational studies have also indicated that green tea intake is inversely related to a risk of CVD. A large, 11-year population-based study involving >40,000 middle-aged individuals from Japan revealed that, compared with non-tea drinkers, those with habitual green tea intake (over two cups daily, approximately $7 \mathrm{oz} /$ day 


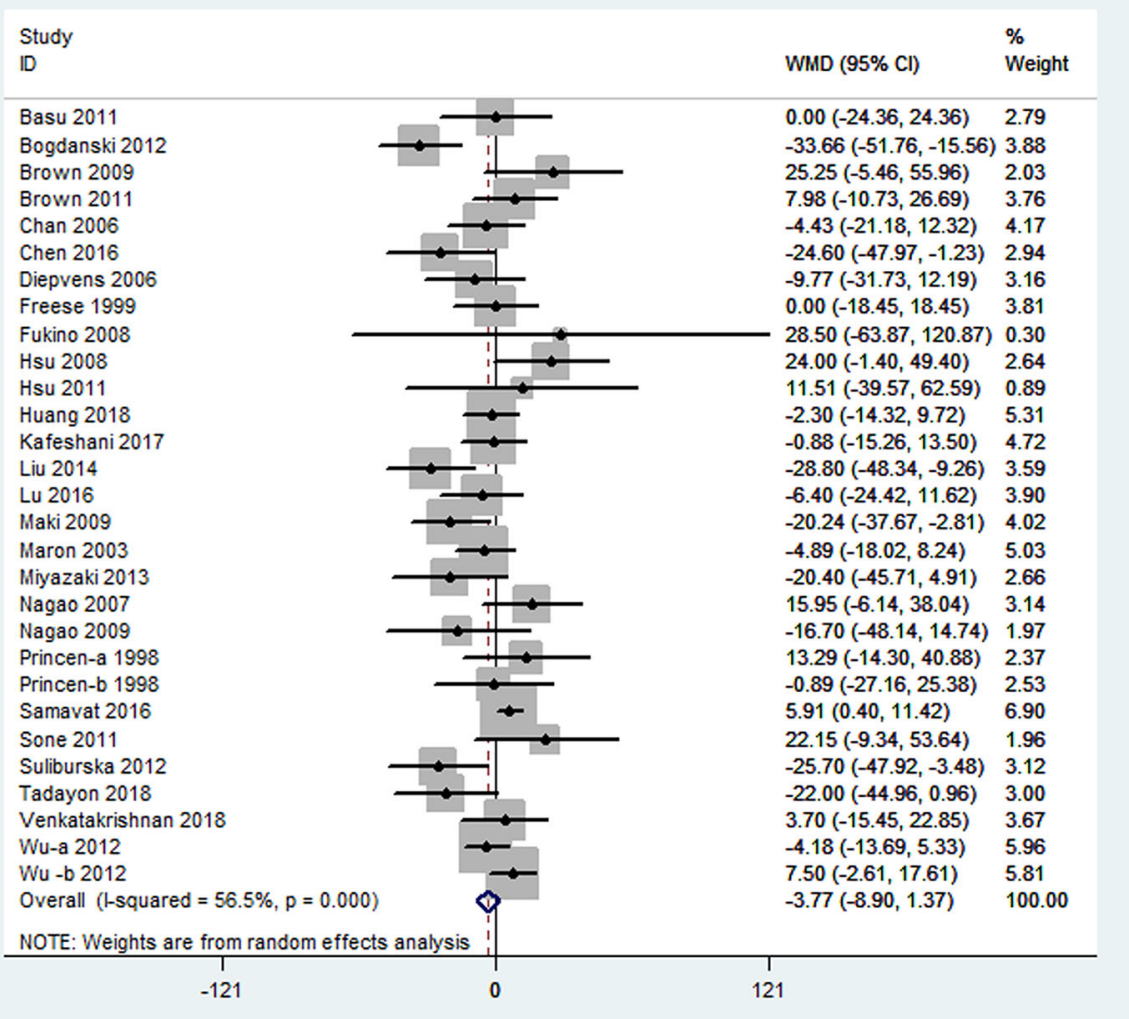

Fig. 6 Meta-analysis of the effects of green tea on triglyceride concentrations. Results from individual trials were pooled with the use of randomeffect models and are expressed as weighted mean differences with $95 \% \mathrm{Cls}$

for 10 years) reduced their risk of death from CVD by 22-33\% [7]. Randomized controlled trials have been performed to determine the effect of green tea on cholesterol concentration; however, the results are conflicting. Some studies have revealed that green tea intake significantly reduced the TC and LDL cholesterol $[24,53]$. In contrast, several other studies reported no positive correlations between green tea intake and reduction in TC and LDL cholesterol $[23,52]$. In addition, most studies suggested that no effect was seen for HDL cholesterol or triglycerides [35, 39], whereas only a few studies suggested a beneficial effect on HDL cholesterol or triglycerides levels [24].

The weighted mean reductions in TC and LDL cholesterol appearing due to green tea supplementation as observed in the present study (TC: $4.66 \mathrm{mg} / \mathrm{dL}$; LDL cholesterol: $4.55 \mathrm{mg} / \mathrm{dL}$ ), corresponding to reductions of $2-5 \%$, might be important for primary prevention of cardiovascular health. Studies have reported that a $1 \%$ reduction in TC or LDL cholesterol was clinically associated with a $2-3 \%$ or $1 \%$ decreased risk of CVD, respectively [60]. Importantly, green tea intake did not negatively affect the serum HDL cholesterol levels. Thus, green tea supplementation mainly reduces the serum TC and LDL cholesterol concentrations but has limited effect on HDL cholesterol.

In this meta-analysis, subgroup analyses suggest that the beneficial effect of green tea was consistent in all the subgroup analyses except for the crossover design subgroups; however, only three trials were included in the crossover design, which were insufficient to make a significant conclusion. In addition, the beneficial effect of green tea intake on LDL cholesterol was also consistently observed in most subgroup analyses except for the caffeine subgroup. A significant reduction in LDL cholesterol was observed in the decaffeination subgroup instead of the caffeine subgroup. As caffeine is naturally present in green tea, whether caffeine intake affects lipid reduction is another potential issue, which continues to have conflicting opinions among previous studies $[61,62]$. The meta-analysis indicated that green tea has no beneficial effect on serum HDL cholesterol, a finding that was consistent in all subgroup analyses. Green tea consumption has a beneficial effect on triglyceride levels in subjects with a longer duration of consumption ( $\geq 12$ weeks); however, the benefit was not significant in other subgroup 
Xu et al. Nutrition Journal $\quad$ (2020) 19:48

Page 11 of 15

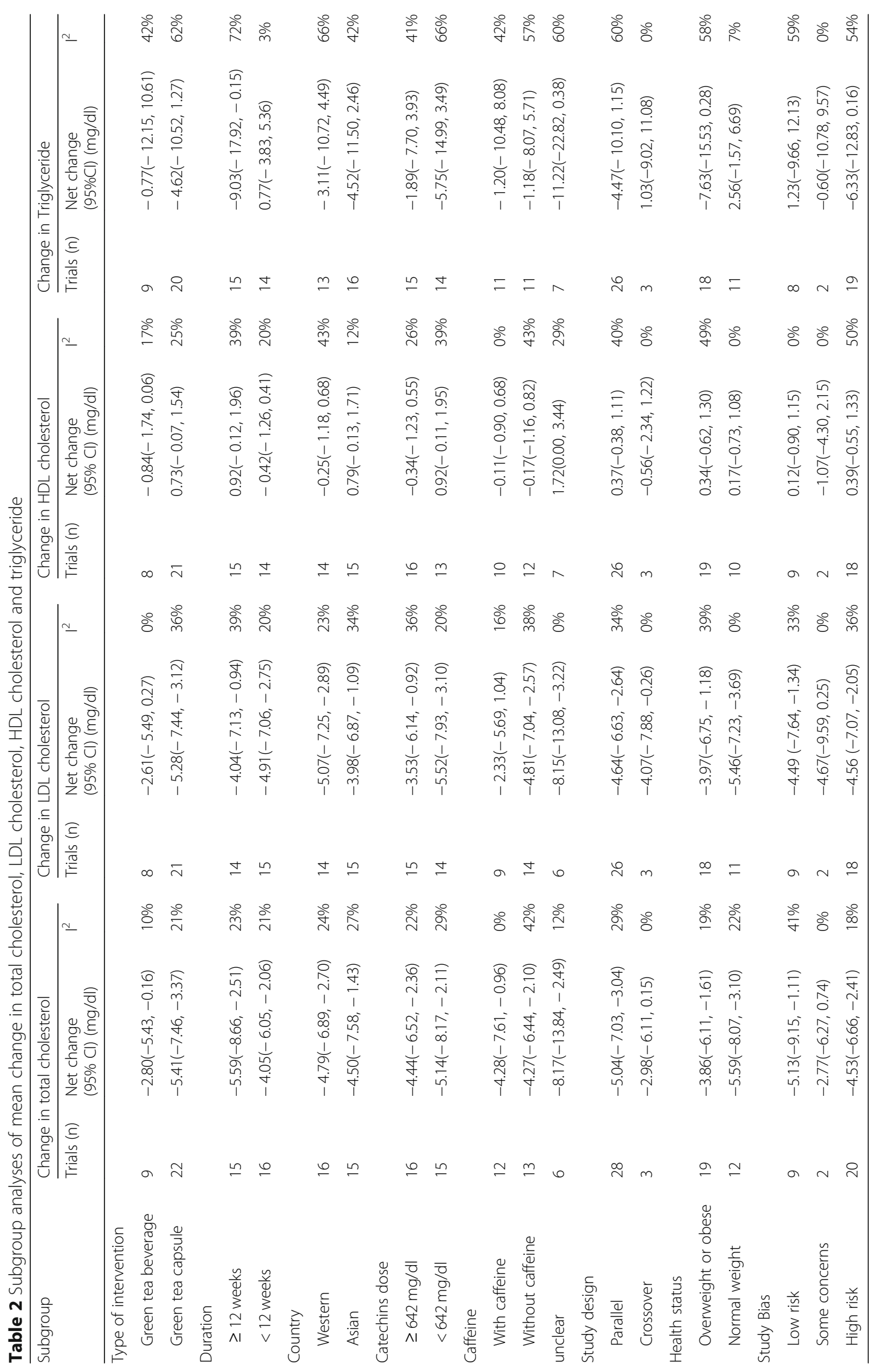




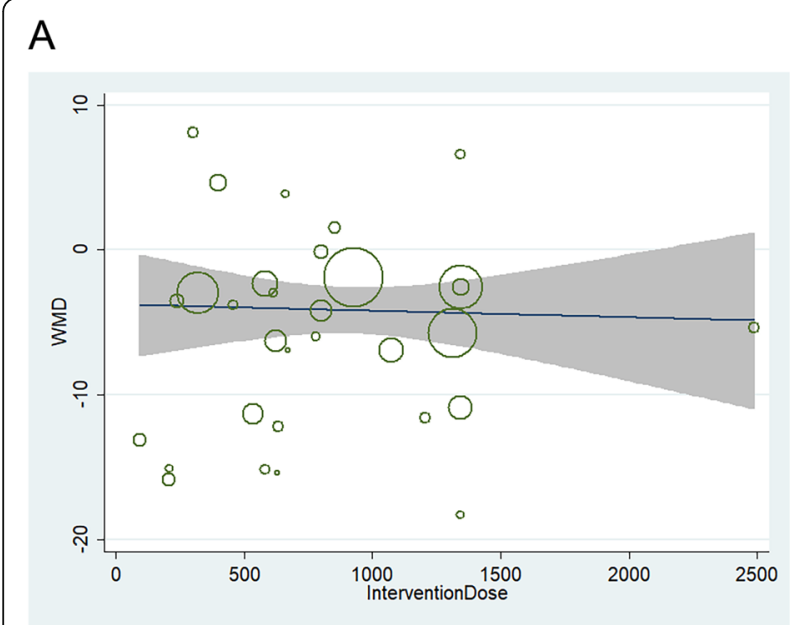

C

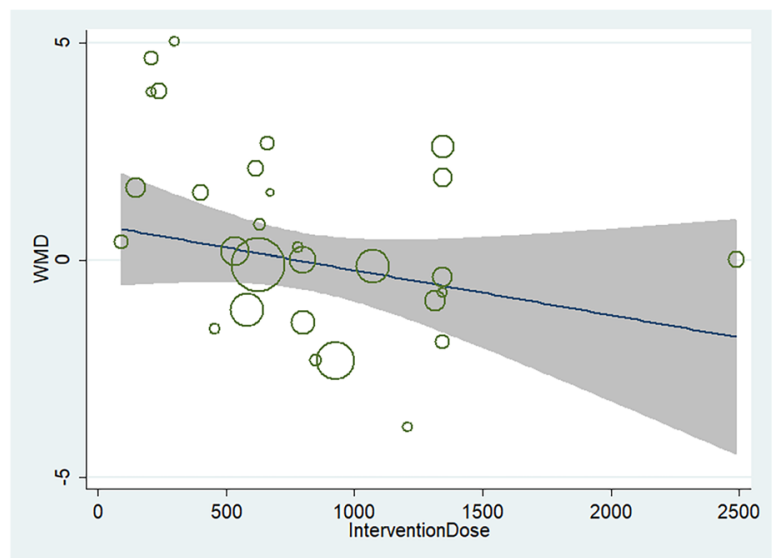

B

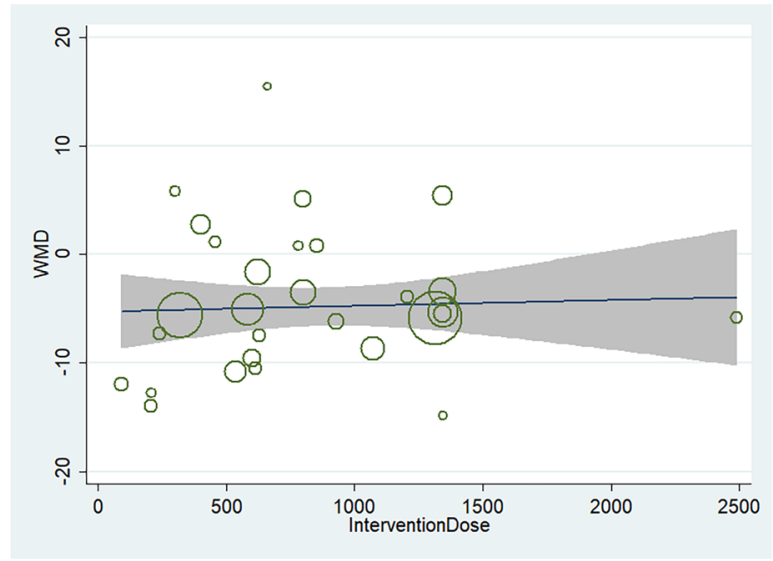

D

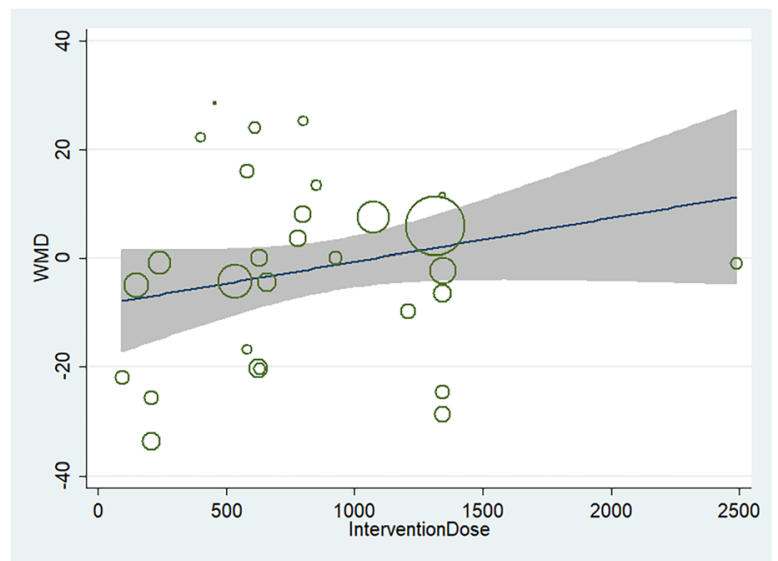

Fig. 7 a Relation between the WMD of total cholesterol and intervention dose in 31 independent randomized controlled comparisons. b Relation between the WMD of LDL cholesterol and intervention dose in 29 independent randomized controlled comparisons. c Relation between the WMD of HDL cholesterol and intervention dose in 29 independent randomized controlled comparisons. $\mathbf{d}$ Relation between the WMD of triglyceride and intervention dose in 29 independent randomized controlled comparisons. Each circle represents a study, telescoped by its weight in the analysis. Meta-regression found no linear relations between WMD in TC $(p=0.94)$, LDL cholesterol $(p=0.69), \mathrm{HDL}$ cholesterol $(p=0.11)$ or triglycerides $(p=0.49)$ and intervention dose

analyses. Because the number of trials available for subgrouping was limited, such analyses should be interpreted with caution. In addition, meta-regression found no significant relations between net change in serum lipid and intervention dose, treatment duration, caffeine content, different ethnicity, intervention type and study design. Larger and longer duration trials with optimally designed treatments and controls are required in the future research.

Our study has certain strengths. First, we only selected RCTs in this meta-analysis, which ensured relatively high-quality data and provided reliable inference about causality. Second, the relatively large number of pooled participants provided us higher statistical power to detect a small treatment effect. Third, results were unlikely to be influenced by publication bias. The results of
Egger's regression tests suggested no significant asymmetry of the funnel plot for the overall effect estimation of mean differences in TC, LDL cholesterol, HDL cholesterol, and triglyceride levels.

Our analyses did have a few limitations. First, the studies had relatively short duration of follow-up, ranging from 3 weeks to 12 months, with a median of 11 weeks, so presumed health benefits cannot be extrapolated beyond the duration of these studies; however, long-term effects are clinically important for lipid profiles and other CVD risk factors. Second, although considerable lowering of TC and LDL cholesterol by green tea intake was observed in our study, we could not determine the optimal dosage of green tea supplementation that would have the greatest impact on improving lipid metabolism, as the catechin dosage varied from 80 to $2488.7 \mathrm{mg} /$ day 
(median: $630.9 \mathrm{mg} /$ day). Third, our meta-analysis did not recognize a safety margin in this study, however, in some studies; concern has been raised as to the safety of high-dose green tea catechin supplementation. Mild side effects were reported in some clinical studies, including gastric upset, mild skin rashes, and abdominal bloating $[26,33]$. In addition, green tea was known to be the major dietary source of oxalate in some patients with kidney oxalate stones [63]. Fourth, we identified large variations in study designs, catechin dosage, ethnic groups, green tea type, baseline health status, and trial quality. Although we did not identify these variations as statistically significant sources of heterogeneity, such heterogeneity may limit the validity of the overall pooled results. In addition, the articles included were all published in English; limited resources prevented us from including articles published in other languages.

\section{Conclusions}

In conclusion, the results of this study indicate that green tea supplementation has a beneficial effect on TC and LDL cholesterol levels in both normal weight subjects and overweight/obese subjects; however, the protective role of green tea against high triglyceride levels was not supported in this study. Additional large prospective cohort studies are needed to provide a more definitive conclusion on the association between routine consumption of green tea and lipid metabolism.

\section{Supplementary information}

Supplementary information accompanies this paper at https://doi.org/10. 1186/s12937-020-00557-5.

Additional file 1: Table S1. Risk of bias for each included studies.

Additional file 2: Figure S1. A. Funnel plot of green tea

supplementation and total cholesterol. B. Funnel plot of green tea

supplementation and LDL cholesterol. C. Funnel plot of green tea

supplementation and HDL cholesterol. D. funnel plot of green tea

supplementation and triglyceride.

\section{Abbreviations}

BP: Blood pressure; Cls: Confidence intervals; CVDs: Cardiovascular diseases; TC: Total cholesterol; LDL: Low-density lipoprotein; HDL: High-density lipoprotein; EGCG: Epigallocatechin gallate; EC: Epicatechin;

EGC: Epigallocatechin; ECG: Epicatechingallate; GTE: Green tea extracts; MDs: Mean differences; PRISMA: Preferred Reporting Items for Systematic Reviews and Meta-Analyses; RCTs: Randomized placebo-controlled trials; SD: Standard Deviation; SE: Standard error; WMD: Weighted mean differences

\section{Acknowledgements}

Not applicable.

\section{Authors' contributions}

RFX searched databases, selected studies, extracted data, analyzed data and wrote the manuscript. KY searched databases and selected studies. SL extracted data. MYD reviewed and edited the manuscript. GZC analyzed data, contributed to the design and discussion, reviewed and edited the manuscript. All authors read and approved the final manuscript.

\section{Funding}

The present study was supported by the National Natural Science Foundation of China (No. 81800334)

\section{Availability of data and materials}

All data generated or analyzed during this study are included in this published article.

Ethics approval and consent to participate

Not applicable.

\section{Consent for publication}

Not applicable.

\section{Competing interests}

The authors declare that they have no competing interests.

\section{Author details}

'Department of Medical Ultrasound, Tongji Hospital, Tongji Medical College, Huazhong University of Science and Technology, Wuhan 430030, People's Republic of China. ${ }^{2}$ Division of Cardiology, Department of Internal Medicine, Tongji Hospital, Tongji Medical College, Huazhong University of Science and Technology, Wuhan 430030, People's Republic of China.

Received: 9 October 2019 Accepted: 22 April 2020

Published online: 20 May 2020

\section{References}

1. Salehi-Abargouei A, Maghsoudi Z, Shirani F, Azadbakht L. Effects of dietary approaches to stop hypertension (DASH)-style diet on fatal or nonfatal cardiovascular diseases--incidence: a systematic review and meta-analysis on observational prospective studies. Nutrition. 2013;29(4):611-8.

2. Jain KS, Kathiravan MK, Somani RS, Shishoo CJ. The biology and chemistry of hyperlipidemia. Bioorg Med Chem. 2007;15(14):4674-99.

3. Yusuf S, Hawken S, Ounpuu S, Dans T, Avezum A, Lanas F, McQueen M, Budaj A, Pais P, Varigos J, et al. Effect of potentially modifiable risk factors associated with myocardial infarction in 52 countries (the INTERHEART study): case-control study. Lancet. 2004;364(9438):937-52.

4. Writing Group M, Lloyd-Jones D, Adams RJ, Brown TM, Carnethon M, Dai S, De Simone G, Ferguson TB, Ford E, Furie K, et al. Heart disease and stroke statistics--2010 update: a report from the American Heart Association. Circulation. 2010;121(7):e46-e215.

5. Last AR, Ference JD, Menzel ER. Hyperlipidemia: drugs for cardiovascular risk reduction in adults. Am Fam Physician. 2017:95(2):78-87.

6. Hunter PM, Hegele RA. Functional foods and dietary supplements for the management of dyslipidaemia. Nat Rev Endocrinol. 2017:13(5):278-88.

7. Kuriyama S, Shimazu T, Ohmori K, Kikuchi N, Nakaya N, Nishino Y, Tsubono Y, Tsuji I. Green tea consumption and mortality due to cardiovascular disease, cancer, and all causes in Japan: the Ohsaki study. JAMA. 2006; 296(10):1255-65

8. Imai K, Nakachi K. Cross sectional study of effects of drinking green tea on cardiovascular and liver diseases. BMJ. 1995:310(6981):693-6.

9. Khan N, Mukhtar H. Tea polyphenols for health promotion. Life Sci. 2007; 81(7):519-33.

10. Oz HS, Chen T, de Villiers WJ. Green tea polyphenols and sulfasalazine have parallel anti-inflammatory properties in colitis models. Front Immunol. 2013; 4:132

11. Klaus S, Pultz S, Thone-Reineke C, Wolfram S. Epigallocatechin gallate attenuates diet-induced obesity in mice by decreasing energy absorption and increasing fat oxidation. Int J Obes. 2005;29(6):615-23.

12. Xing $L$, Zhang $H$, Qi R, Tsao R, Mine $Y$. Recent advances in the understanding of the health benefits and molecular mechanisms associated with green tea polyphenols. J Agric Food Chem. 2019;67(4):1029-43.

13. Zheng $X X, X u Y L$, Li SH, Liu XX, Hui R, Huang XH. Green tea intake lowers fasting serum total and LDL cholesterol in adults: a meta-analysis of 14 randomized controlled trials. Am J Clin Nutr. 2011:94(2):601-10.

14. Alves Ferreira M, Oliveira Gomes AP, Guimaraes de Moraes AP, Ferreira Stringhini ML, Mota JF, Siqueira Guedes Coelho A, Borges Botelho P. Green tea extract outperforms metformin in lipid profile and glycaemic control in overweight women: a double-blind, placebo-controlled, randomized trial. Clin Nutr ESPEN. 2017;22:1-6. 
15. Bertipaglia de Santana M, Mandarino MG, Cardoso JR, Dichi I, Dichi JB, Camargo AE, Fabris BA, Rodrigues RJ, Fatel EC, Nixdorf SL, et al. Association between soy and green tea (Camellia sinensis) diminishes hypercholesterolemia and increases total plasma antioxidant potential in dyslipidemic subjects. Nutrition. 2008;24(6):562-8.

16. Amozadeh $H$, Shabani $R$, Nazari $M$. The effect of aerobic training and green tea supplementation on cardio metabolic risk factors in overweight and obese females: a randomized trial. Int J Endocrinol Metab. 2018;16(4): e60738.

17. Stroup DF, Berlin JA, Morton SC, Olkin I, Williamson GD, Rennie D, Moher D, Becker BJ, Sipe TA, Thacker SB. Meta-analysis of observational studies in epidemiology: a proposal for reporting. Meta-analysis of observational studies in epidemiology (MOOSE) group. JAMA. 2000;283(15):2008-12.

18. Sterne JAC, Savovic J, Page MJ, Elbers RG, Blencowe NS, Boutron I, Cates CJ, Cheng HY, Corbett MS, Eldridge SM, et al. RoB 2: a revised tool for assessing risk of bias in randomised trials. BMJ. 2019;366:14898.

19. Anzures-Cabrera J, Sarpatwari A, Higgins JP. Expressing findings from metaanalyses of continuous outcomes in terms of risks. Stat Med. 2011;30(25): 2967-85.

20. Follmann D, Elliott $P$, Suh I, Cutler J. Variance imputation for overviews of clinical trials with continuous response. J Clin Epidemiol. 1992;45(7):769-73.

21. Higgins JP, Thompson SG, Deeks JJ, Altman DG. Measuring inconsistency in meta-analyses. BMJ. 2003;327(7414):557-60.

22. Egger M, Davey Smith G, Schneider M, Minder C. Bias in meta-analysis detected by a simple, graphical test. BMJ. 1997;315(7109):629-34.

23. Basu A, Du M, Sanchez K, Leyva MJ, Betts NM, Blevins S, Wu M, Aston CE, Lyons TJ. Green tea minimally affects biomarkers of inflammation in obese subjects with metabolic syndrome. Nutrition. 2011;27(2):206-13.

24. Bogdanski P, Suliburska J, Szulinska M, Stepien M, Pupek-Musialik D, Jablecka A. Green tea extract reduces blood pressure, inflammatory biomarkers, and oxidative stress and improves parameters associated with insulin resistance in obese, hypertensive patients. Nutr Res. 2012;32(6):421-7.

25. Brown AL, Lane J, Coverly J, Stocks J, Jackson S, Stephen A, Bluck L, Coward A, Hendrickx $\mathrm{H}$. Effects of dietary supplementation with the green tea polyphenol epigallocatechin-3-gallate on insulin resistance and associated metabolic risk factors: randomized controlled trial. Br J Nutr. 2009;101(6): 886-94.

26. Brown AL, Lane J, Holyoak C, Nicol B, Mayes AE, Dadd T. Health effects of green tea catechins in overweight and obese men: a randomised controlled cross-over trial. Br J Nutr. 2011;106(12):1880-9.

27. Chan CC, Koo MW, Ng EH, Tang OS, Yeung WS, Ho PC. Effects of Chinese green tea on weight, and hormonal and biochemical profiles in obese patients with polycystic ovary syndrome--a randomized placebo-controlled trial. J Soc Gynecol Investig. 2006;13(1):63-8.

28. Chen IJ, Liu CY, Chiu JP, Hsu CH. Therapeutic effect of high-dose green tea extract on weight reduction: a randomized, double-blind, placebocontrolled clinical trial. Clin Nutr. 2016;35(3):592-9.

29. Diepvens K, Kovacs EM, Vogels N, Westerterp-Plantenga MS. Metabolic effects of green tea and of phases of weight loss. Physiol Behav. 2006;87(1): 185-91.

30. Frank J, George TW, Lodge JK, Rodriguez-Mateos AM, Spencer JP, Minihane AM, Rimbach G. Daily consumption of an aqueous green tea extract supplement does not impair liver function or alter cardiovascular disease risk biomarkers in healthy men. J Nutr. 2009;139(1):58-62.

31. Freese R, Basu S, Hietanen E, Nair J, Nakachi K, Bartsch H, Mutanen M. Green tea extract decreases plasma malondialdehyde concentration but does not affect other indicators of oxidative stress, nitric oxide production, or hemostatic factors during a high-linoleic acid diet in healthy females. Eur J Nutr. 1999;38(3):149-57.

32. Fukino Y, Ikeda A, Maruyama K, Aoki N, Okubo T, Iso H. Randomized controlled trial for an effect of green tea-extract powder supplementation on glucose abnormalities. Eur J Clin Nutr. 2008;62(8):953-60.

33. Hsu CH, Tsai TH, Kao YH, Hwang KC, Tseng TY, Chou P. Effect of green tea extract on obese women: a randomized, double-blind, placebo-controlled clinical trial. Clin Nutr. 2008;27(3):363-70.

34. Hsu CH, Liao YL, Lin SC, Tsai TH, Huang CJ, Chou P. Does supplementation with green tea extract improve insulin resistance in obese type 2 diabetics? A randomized, double-blind, and placebo-controlled clinical trial. Altern Med Rev. 2011;16(2):157-63.

35. Huang LH, Liu CY, Wang LY, Huang CJ, Hsu CH. Effects of green tea extract on overweight and obese women with high levels of low density-lipoprotein-cholesterol (LDL-C): a randomised, double-blind, and cross-over placebo-controlled clinical trial. BMC Complement Altern Med. 2018;18(1):294.

36. Kafeshani M, Entezari MH, Karimian J, Pourmasoumi M, Maracy MR, Amini MR, Hadi A. A comparative study of the effect of green tea and sour tea on blood pressure and lipid profile in healthy adult men. ARYA Atheroscler. 2017;13(3):109-16

37. Lee TM, Charng MJ, Tseng CD, Lai LP. A double-blind, randomized, placebocontrolled study to evaluate the efficacy and safety of STA-2 (green tea polyphenols) in patients with chronic stable angina. Acta Cardiol Sin. 2016; 32(4):439-49.

38. Liu CY, Huang CJ, Huang LH, Chen IJ, Chiu JP, Hsu CH. Effects of green tea extract on insulin resistance and glucagon-like peptide 1 in patients with type 2 diabetes and lipid abnormalities: a randomized, double-blinded, and placebo-controlled trial. PLoS One. 2014;9(3):e91163.

39. Lu PH, Hsu CH. Does supplementation with green tea extract improve acne in post-adolescent women? A randomized, double-blind, and placebocontrolled clinical trial. Complement Ther Med. 2016;25:159-63.

40. Maki KC, Reeves MS, Farmer M, Yasunaga K, Matsuo N, Katsuragi Y, Komikado M, Tokimitsu I, Wilder D, Jones F, et al. Green tea catechin consumption enhances exercise-induced abdominal fat loss in overweight and obese adults. J Nutr. 2009;139(2):264-70.

41. Maron DJ, Lu GP, Cai NS, Wu ZG, Li YH, Chen H, Zhu JQ, Jin XJ, Wouters BC, Zhao J. Cholesterol-lowering effect of a theaflavin-enriched green tea extract: a randomized controlled trial. Arch Intern Med. 2003;163(12):1448-53.

42. Mielgo-Ayuso J, Barrenechea L, Alcorta P, Larrarte E, Margareto J, Labayen I. Effects of dietary supplementation with epigallocatechin-3-gallate on weight loss, energy homeostasis, cardiometabolic risk factors and liver function in obese women: randomised, double-blind, placebo-controlled clinical trial. Br J Nutr. 2014;111(7):1263-71.

43. Miyazaki R, Kotani K, Ayabe M, Tsuzaki K, Shimada J, Sakane N, Takase H, Ichikawa $\mathrm{H}$, Yonei $\mathrm{Y}$, Ishii K. Minor effects of green tea catechin supplementation on cardiovascular risk markers in active older people: a randomized controlled trial. Geriatr Gerontol Int. 2013;13(3):622-9.

44. Nagao T, Hase T, Tokimitsu I. A green tea extract high in catechins reduces body fat and cardiovascular risks in humans. Obesity (Silver Spring). 2007; 15(6):1473-83.

45. Nagao T, Meguro S, Hase T, Otsuka K, Komikado M, Tokimitsu I, Yamamoto T, Yamamoto K. A catechin-rich beverage improves obesity and blood glucose control in patients with type 2 diabetes. Obesity (Silver Spring). 2009;17(2):310-7.

46. Nantz MP, Rowe CA, Bukowski JF, Percival SS. Standardized capsule of Camellia sinensis lowers cardiovascular risk factors in a randomized, doubleblind, placebo-controlled study. Nutrition. 2009;25(2):147-54.

47. Princen HM, van Duyvenvoorde W, Buytenhek R, Blonk C, Tijburg LB, Langius JA, Meinders AE, Pijl H. No effect of consumption of green and black tea on plasma lipid and antioxidant levels and on LDL oxidation in smokers. Arterioscler Thromb Vasc Biol. 1998;18(5):833-41.

48. Samavat $H$, Newman AR, Wang R, Yuan JM, Wu AH, Kurzer MS. Effects of green tea catechin extract on serum lipids in postmenopausal women: a randomized, placebo-controlled clinical trial. Am J Clin Nutr. 2016;104(6): 1671-82.

49. Sone T, Kuriyama S, Nakaya N, Hozawa A, Shimazu T, Nomura K, Rikimaru S, Tsuji I. Randomized controlled trial for an effect of catechin-enriched green tea consumption on adiponectin and cardiovascular disease risk factors. Food Nutr Res. 2011;55.

50. Suliburska J, Bogdanski P, Szulinska M, Stepien M, Pupek-Musialik D, Jablecka A. Effects of green tea supplementation on elements, total antioxidants, lipids, and glucose values in the serum of obese patients. Biol Trace Elem Res. 2012;149(3):315-22.

51. Tadayon M, Movahedi S, Abedi P, Syahpoosh A. Impact of green tea extract on serum lipid of postmenopausal women: a randomized controlled trial. J Tradit Complement Med. 2018;8(3):391-5.

52. Venkatakrishnan K, Chiu HF, Cheng JC, Chang YH, Lu YY, Han YC, Shen YC, Tsai KS, Wang CK. Comparative studies on the hypolipidemic, antioxidant and hepatoprotective activities of catechin-enriched green and oolong tea in a double-blind clinical trial. Food Funct. 2018;9(2):1205-13.

53. Wu AH, Spicer D, Stanczyk FZ, Tseng CC, Yang CS, Pike MC. Effect of 2month controlled green tea intervention on lipoprotein cholesterol, glucose, and hormone levels in healthy postmenopausal women. Cancer Prev Res (Phila). 2012;5(3):393-402. 
54. Cao SY, Zhao CN, Gan RY, Xu XY, Wei XL, Corke H, Atanasov AG, Li HB, Effects and mechanisms of tea and its bioactive compounds for the prevention and treatment of cardiovascular diseases: an updated review. Antioxidants (Basel). 2019;8(6):166

55. Cheng H, Xu N, Zhao W, Su J, Liang M, Xie Z, Wu X, Li Q. (-)-Epicatechin regulates blood lipids and attenuates hepatic steatosis in rats fed high-fat diet. Mol Nutr Food Res. 2017;61(11).

56. Wang W, Zhang ZZ, Wu Y, Wang RQ, Chen JW, Chen J, Zhang Y, Chen YJ, Geng M, Xu ZD, et al. (-)-Epigallocatechin-3-Gallate ameliorates atherosclerosis and modulates hepatic lipid metabolic gene expression in Apolipoprotein E knockout mice: involvement of TTC39B. Front Pharmacol. 2018;9:195.

57. Suzuki-Sugihara N, Kishimoto Y, Saita E, Taguchi C, Kobayashi M, Ichitani M, Ukawa Y, Sagesaka YM, Suzuki E, Kondo K. Green tea catechins prevent lowdensity lipoprotein oxidation via their accumulation in low-density lipoprotein particles in humans. Nutr Res. 2016;36(1):16-23.

58. Bursill CA, Roach PD. Modulation of cholesterol metabolism by the green tea polyphenol (-)-epigallocatechin gallate in cultured human liver (HepG2) cells. J Agric Food Chem. 2006;54(5):1621-6.

59. Koo SI, Noh SK. Green tea as inhibitor of the intestinal absorption of lipids: potential mechanism for its lipid-lowering effect. J Nutr Biochem. 2007;18(3): 179-83.

60. Expert Panel on Detection E. Treatment of high blood cholesterol in a: executive summary of the third report of the National Cholesterol Education Program (NCEP) expert panel on detection, evaluation, and treatment of high blood cholesterol in adults (adult treatment panel III). JAMA. 2001;285(19):2486-97.

61. Giggey PP, Wendell CR, Zonderman AB, Waldstein SR. Greater coffee intake in men is associated with steeper age-related increases in blood pressure. Am J Hypertens. 2011;24(3):310-5.

62. Potter JF, Haigh RA, Harper GD, Fotherby M, Hurd S, Macdonald IA. Blood pressure, plasma catecholamine and renin responses to caffeine in elderly hypertensives. J Hum Hypertens. 1993;7(3):273-8.

63. Gasinska A, Gajewska D. Tea and coffee as the main sources of oxalate in diets of patients with kidney oxalate stones. Rocz Panstw Zakl Hig. 2007; 58(1):61-7.

\section{Publisher's Note}

Springer Nature remains neutral with regard to jurisdictional claims in published maps and institutional affiliations.

Ready to submit your research? Choose BMC and benefit from:

- fast, convenient online submission

- thorough peer review by experienced researchers in your field

- rapid publication on acceptance

- support for research data, including large and complex data types

- gold Open Access which fosters wider collaboration and increased citations

- maximum visibility for your research: over $100 \mathrm{M}$ website views per year

At $\mathrm{BMC}$, research is always in progress.

Learn more biomedcentral.com/submissions 